\title{
PLANNING LONG-TERM MANAGEMENT FOR HISTORIC CITIES. THE ROCK INTEGRATED AND SUSTAINABLE MANAGEMENT PLAN
}

\author{
ANDREA BOERI, DANILA LONGO, CHIARA MARIOTTI \& ROSSELLA ROVERSI \\ Alma Mater Studiorum, University of Bologna, Department of Architecture.
}

\begin{abstract}
The practice of management, although quite recent, embodies one of the major challenges for planning sustainable historic cities. Environmental, climatic, social and cultural issues affecting historic contexts, make management a fundamental process in balancing sustainable development and heritage conservation over time. In this framework, the ROCK - Regeneration and Optimisation of Cultural heritage in creative and Knowledge cities - project (H2020, n. 730280) aims at developing Cultural Heritage-led regeneration strategies capable of ensuring streams of long-lasting structured actions after the end of the project. Involving 10 European cities under the coordination of the Municipality of Bologna with the core scientific support of the University of Bologna, this project is designing a long-term management tool and testing its innovative pathway across the EU. Thus, this paper will focus on the genesis, construction and implementation of the ROCK Integrated Management Plan (IMP) as vital toolkit for developing, over time, sustainable urban procedures in the historic cities focused on the essential role of tangible and intangible heritage. Based on the UNESCO Management Plans, the existing literature and on several international reference experiences, ROCK IMP embeds the research-action-research methodology that underlies the whole project. Following this innovative circular approach, a preliminary set of goals and actions were selected (research), then implemented trough pilot interventions, co-designed and co-created with local administrations, stakeholders and citizens (action), and finally updated, considering the impacts of the performed actions to recalibrate the process and build scenarios for the IMP (research). As it is an ongoing process, this paper will appraise its state of the art, highlighting the potential and criticalities and describing what has been done in the city of Bologna so far.

Keywords: Cultural Heritage, governance, historic cities, integrated management, long-term planning, urban sustainable regeneration.
\end{abstract}

\section{INTRODUCTION}

'Urban decay, social conflict and low living standards are not uncommon in many of European historic city centres. Is it possible to breathe new life into these areas while doing it in a sustainable way?' [1].

This is the starting point of a very recent report published by the European Commission and focused on scientific research advances concerning the future of the historic built environment. A very relevant aspect for the present study is not only the affirmative statement of the European Commission on the matter, but the exemplary project presented for facing this challenge. This is the European project 'ROCK - Regeneration and Optimisation of Cultural heritage in creative and Knowledge cities' - (grant agreement $\left.\mathrm{n}^{\circ} 730280\right)$, funded under the Horizon 2020 Work Programme 2016-2017 Climate action, environments, resource efficiency and raw materials, topic Cultural Heritage as a driver for sustainable growth (SC5-21) as part of the call Greening the Economy, third Horizon thematic pillar on Societal Challenge [2].

ROCK develops innovation in Cultural Heritage $(\mathrm{CH})$ through a collaborative and systemic approach that promotes $\mathrm{CH}$-led regeneration strategies for historic city centres and 
supports the demo areas' transformation into Creative, Cultural and Sustainable Districts. In ROCK vision, cultural heritage is not an inactive and burdensome factor but 'a unique and powerful engine of regeneration, sustainable development and economic growth for the whole city' [3]. Starting from this assumption, ROCK expressed the ambition to go over the three years of the project - whose end is scheduled in May 2020 - in order to ensure future streams of long-lasting structured actions based on its pilot experience. To meet such a goal, a specific tool for achieving outputs and outcomes of successful management is been tested and developed: the ROCK Integrated Management Plan (IMP).

As development without conservation cannot be sustainable, while conservation cannot succeed without development to sustain its efforts [4], an integrated and long-term system of urban governance is today increasingly urgent. From this point of view, ROCK IMP represents one of the main output and, at the same time, the most important legacy of this research. The relevance of the research-action implemented by ROCK has been confirmed during the high-level H2020 Conference Innovation \& Cultural Heritage held in Brussels on 20th March 2018: the project has been invited to participate to the conference organised by the European Commission to celebrate the European Year of Cultural Heritage and has been presented as a significant model of innovation for sustainable urban development and management [5].

\section{OBJECTIVE AND METHODOLOGY}

The objective of this paper is to describe the process of genesis, construction and implementation of ROCK Integrated Management Plan. As ROCK is an ongoing project, potential, criticalities and still unresolved issues regarding the current state of the art of this work are outlined.

The aim is to identify some of the most promising orientations in the field of urban regeneration, planning long-term management for the 'Historic Urban Landscape' [6], understanding the evolving nature of today's cities and addressing it in a sustainable way. Working on the stratified context of the European cities means facing a whole range of social, economic, environmental and conservation criticalities (for instance physical decay, social conflicts, environmental pressures, economic crisis, lack of security, ineffective management of spaces and underuse of existing buildings), but also benefitting from the presence of tangible and intangible cultural heritage as a fundamental driver of continuity and progress. For this reason, ROCK can be consider part of an experimental sector of cultural heritage research that bets on the possibility to balance into a unique project the major challenge for the future of European historic cities: managing the systemic urban transformation between conservation and innovation.

This paper is structured in two core sections. The first one offers a general overview on the concept of 'management' with particular reference to recent guiding principles for managing cultural heritage developed by international institutions such as UNESCO, ICCROM, ICOMOS, IUNC to name but a few. The second section deepens the ROCK experience of management through the description of the Integrated Management Plan, especially the design process for its construction. This section also illustrates similarities and differences between ROCK IMPs and other Management Plans already codified by the existing literature - in particular UNESCO Management Plans. Last but not least, first experimentations in Bologna ROCK city are presented in order to illustrate a concrete example of implemented actions.

The study is based both on a desk research, especially for the first section, and on a direct research experience on the ROCK project, mainly with regard to the second one. 


\section{MANAGING CULTURAL HERITAGE COMPLEXITY}

\subsection{The concept of 'management'}

The concept of 'management' is comparatively recent having its root in the Convention concerning the Protection of the World Cultural and Natural Heritage as 'the duty of ensuring the identification, protection, conservation, presentation and transmission to future generations of the cultural and natural heritage' [7]. Since then, the need to achieve these purposes has become more and more complex due to the increasing pressure on the contemporary world and to the widening definition of Cultural Heritage [8].

As far as the European polices for $\mathrm{CH}$ are concerned, the trend is to recommend 'a holistic research agenda and an inclusive interdisciplinary approach' [9], by means of a new vision and mission in heritage management. In this context, the historic built environment is defined as an inclusive and comprehensive platform that cannot be understood or managed except through an approach that embraces all its complexity.

The main aim is to raise understanding of the integration of urban and heritage planning in multilevel governance, exploring ways to best reveal the relations between supranational and subnational policy [4]. In this perspective, new targets have been established such as the importance of a common ground to define, assess and improve management systems, the mutual exchange of good practices and the evolution of improved management approaches as well as the provision of practical guidance and tools for day-to-day management practice recognizing the increased number of stakeholders involved and the awareness of the diversity of management problems linked to each specific country [10].

\subsection{The UNESCO Management Plan}

According to these key-assumptions, UNESCO, with the support of other international institutions, published The World Heritage Resource Manual: Managing Cultural World Heritage, whose aims is to understand the management systems and the ways to improve them for managing cultural heritage effectively. The Manual identifies nine basic components and clusters them in three interlinked pillars [10] (Fig. 1):

- 3 elements: legal framework, institutional framework and resources;

- 3 processes: planning, implementation and monitoring;

- 3 results: outcomes, outputs and improvements.

The Management System is the result of the combined effect of all these components. Its conceptual structure provides a common framework and helps heritage practitioners, policy-makers, communities, local stakeholders and citizens to control the systemic evolution of heritage processes by ensuring conservation and enhancement of its Outstanding Universal Value. As Outstanding Universal Value is meant 'cultural and/or natural significance which is so exceptional as to transcend national boundaries and to be of common importance for present and future generations of all humanity' [11].

The Management System is fully reflected in the Management Plan, intended as 'the guidance document developed within, and describing, a particular management system' [10]. As defined in Appendix A of the above-mentioned Manual, it is 'a relatively new tool which determines and establishes the appropriate strategy, objectives, actions and implementation 


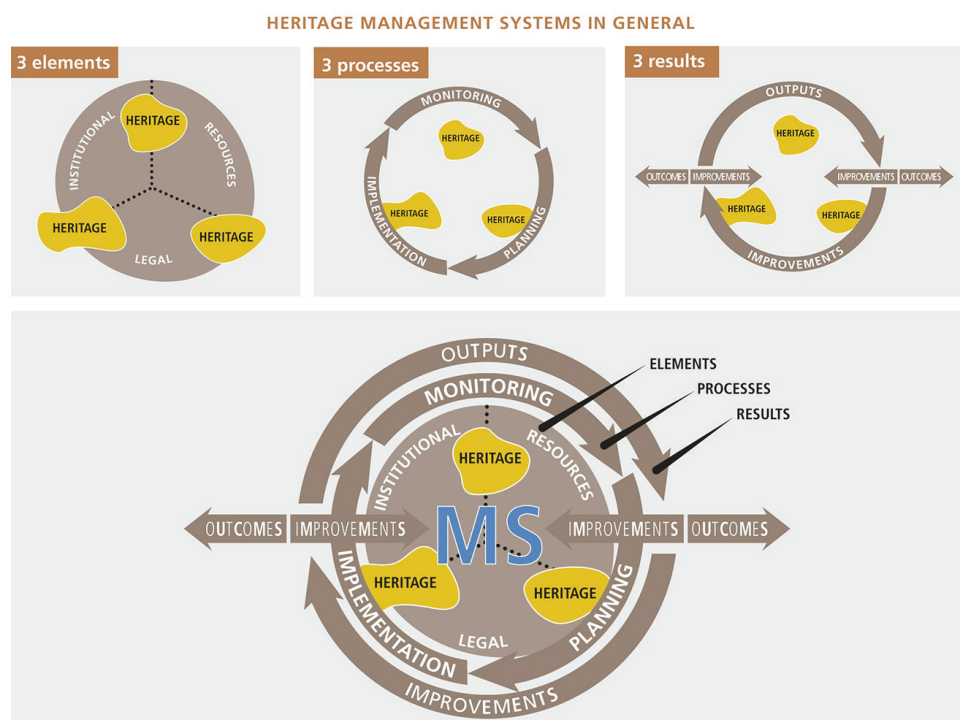

Figure 1: UNESCO Heritage Management System.

Source: UNESCO et al. 2013 [10].

structures to manage and, where appropriate, develop cultural heritage in an effective and sustainable way so that its values are retained for present and future use and appreciation. It balances and coordinates the cultural heritage needs with the needs of the 'users' of the heritage and the responsible governmental and/or private/community bodies' [10].

Therefore, a responsive Management Plan should be unique and site-specific, cyclical to evaluate its process so as to adjust its ongoing activities and to inform the next cycle, interacting with other Management Systems or with their components, sufficiently flexible to deal with unforeseeable events (e.g. natural disaster and financial changes), common and shared as it is shaped on inputs of the different actors involved, dynamic and built through a participatory approach, drafted for the long-term future of the property, realistic and sustainable to assure multi-level benefits respecting the past, taking advantage of the present and not damaging the future, and last but not least, regularly reviewed and updated in order to better respond to evolving challenges [10,12].

Such principles have been translated into several Management Plans aiming at balancing conservation and sustainable development as well as at safeguarding the Outstanding Universal Value, the authenticity and integrity of all sites included in the UNESCO World Heritage Lists. A still open challenge is the opportunity to transfer and extend this model to wider contexts, for instance to historic cities across Europe. The ROCK project is founded on this challenge.

\section{PLANNING INTEGRATED MANAGEMENT FOR HISTORIC CITIES}

\subsection{The H2020-ROCK project}

ROCK is the European project funded under the Horizon 2020 Programme in 2017. ROCK stands for Regeneration and Optimisation of Cultural heritage in creative and Knowledge 
cities. Its mission supports one of the four core actions recommended by the European Union (EU) to 'reinforce the role of heritage as part of Europe's underlying socio-economic, cultural and natural capital', that is, Heritage Led Urban Regeneration [13]. This project has received funding of about 10 million euros and currently involves 32 partners from 13 European countries and 10 historic cities of the Union, coordinated by the Municipality of Bologna in close scientific collaboration with the Alma Mater Studiorum University.

ROCK focuses on historic city centres as 'extraordinary laboratories' where testing systemic transformations into Creative, Cultural and Sustainable Districts through shared generation of new sustainable environmental, social, economic processes [3]. Starting from a selection of three demonstrative areas in Bologna, Lisbon and Skopje, the project aims at overcoming the physical decay, social conflicts and poor life quality affecting these areas, and at promoting strategies to spread knowledge, experience and good practices in order to help municipality leaders and the local ecosystem of stakeholders in developing the vision, and gaining the skills, to be successful at using heritage to regenerate their cities $[3,13]$.

This project is based on the mutual exchange of meaningful experiences of socio-cultural transformations between the 10 cities involved: 7 Role Model Cities (Athens, Cluj-Napoca, Eindhoven, Liverpool, Lyon, Turin and Vilnius), which have already implemented vital processes of regeneration, and 3 Replicator Cities (Bologna, Lisbon and Skopje) where similar successful models can be transferred in relation to their local contexts.

ROCK pilot process is driven by a research-action-research methodology that marks the essential role of the research in heritage development procedures: the idea is to implement site-specific actions, record their feedbacks, verify their impacts, and recalibrate them for the future, again with the support of the research.

The pilot process implementation is structured around three main pillars: accessibility, sustainability and new collaborations for productions; within each of them, detailed thematic actions have been clustered (e.g. lightings, wayfinding, greening, business matching, adaptive reuse, knowledge building and so on). In addition, key components of the project are the enabling technologies - especially Information and Communication Technologies for cultural heritage promotion and dissemination such as Virtual and Augmented Reality - and the attention to the environment, complementary to both the social and the conservation ones.

\subsection{Towards ROCK Integrated Management Plan}

On 20th May 2014 the Council of the European Union adopted a fundamental document, which has recognized Cultural Heritage as 'a strategic resource for a sustainable Europe' [14]. In line with the EU Conclusions and as already stated, ROCK develops innovation in the field of cultural heritage management through the construction of a key tool for planning long-term Cultural Heritage-led regeneration strategies in historic city centres.

The ROCK Integrated Management Plan is designed to ensure the right balance between cultural heritage conservation and urban sustainable growth in a long-term perspective. For this reason, it is intended as a very practical, easy-to-understand and easy-to-use toolkit, and it is based on the existing literature as well as on virtuous management experiences already implemented. The UNESCO Management Plan represents its main reference point, especially those drafted by the Role Model Cities: Liverpool, Lyon and Vilnius [15-17]. After a preliminary phase of knowledge building, ROCK adopts principles and structure of UNESCO Plans while introducing two main innovative aspects. 
The first innovation regards the use of a new attribute. Compared to the UNESCO Management Plan, the ROCK one is called Integrated because it supports a multi-level integration process:

- it integrates the existing city plans and procedures without being an additional governance tool;

- it integrates all relevant categories of users interested in urban policies and $\mathrm{CH}$ research, thus facilitating trans-disciplinary and trans-sectorial collaborations;

- and it continuously integrates research and action phases.

The second innovation coming from ROCK is directly linked to this latter aspect as the result of the research-action-research methodology. In fact, the design process of ROCK Integrated Management Plan is based on this circular approach including:

- a first research phase aimed at identifying needs, key stakeholders, key areas and key actions and enablers, in order to properly prepare the concrete action planning and implementation. This preliminary set of actions helps cities to build scenarios to predict and simulate different possibilities of $\mathrm{CH}$-led sustainable growth with regard to the three main pillars of the project (accessibility, sustainability and new collaboration). A participatory approach chains the co-designed activities, deriving from the mutual exchange between Role Model and Replicator cities, as well as the Living Lab meetings;

- an action phase, focused on the implementation of pilot actions according to the first draft of scenarios assumed by Replicators and supported by a mixed bottom-up and topdown initiatives. The pilot implementation can meet constraints and barriers, make arise more needs, problems and manifest the necessity of adjustments. Therefore, the process foresees additional research activities;

- a second research phase, finalized to the definition of more detailed scenarios capable of taking into account new assumptions and needs deriving from the implemented pilot actions.

ROCK Integrated Management Plan grafts itself on this second research phase: hence, the scenario construction is the preliminary and crucial work that supports cities in defining their IMP. The major aim of ROCK IMPs is to facilitate the transition from the experimental activities carried out during the project to a long-term structured action programme for the future. In order to achieve this objective, it is composed of two complementary parts:

- an Operating Manual (one for all Replicators) including the methodology and the common structure underlining ROCK Integrated Management Plan - knowledge gain, vision definition, action plan, future perspectives -;

- and three site-specific Management Plans (one for each Replicator) to be compiled during the life time of the $\mathrm{H} 2020$ project and delivered at the end of the entire research experience.

According to these principles, ROCK Integrated Management Plan launches a process founded on a horizontal integration of actors - a mix of planned and emergent elements, self-organized activities coalescing into a shared model of local development, and a cross-sectoral coordination of polices, plans and procedures for the historic site implementation. Such 
a methodology is meant to be applied at the urban scale, nevertheless ROCK proposes a first application in smaller and more specific contexts: pilot actions are carried out at the district scale that offers an intermediate dimension useful for supporting projects and monitoring results effectively [18].

At present, the three Replicator Cities are working synergistically to build their respective Management Plans from which to derive the contents of the Operating Manual. To facilitate the construction phase, which is still in progress, some practical factsheets and several collective meetings have been developed for guiding, step by step, the actors involved in the implementation and integration process of this new model of urban governance.

As a matter of fact, the Integrated Management Plan mainly supports the ROCK regeneration whose aim is to activate a new, systemic and circular flow of urban transformations. As shown in the graphic concept (Fig. 2), it turns around the predictive macro-scenarios on accessibility, sustainability and new collaborations for production that really make real the revitalization of spaces and relationships into historic cities.

Conceptually, each scenario can be traced back to a series of universal guiding principles that have a different degree of relevance in different contexts and that must be declined according to each local site.

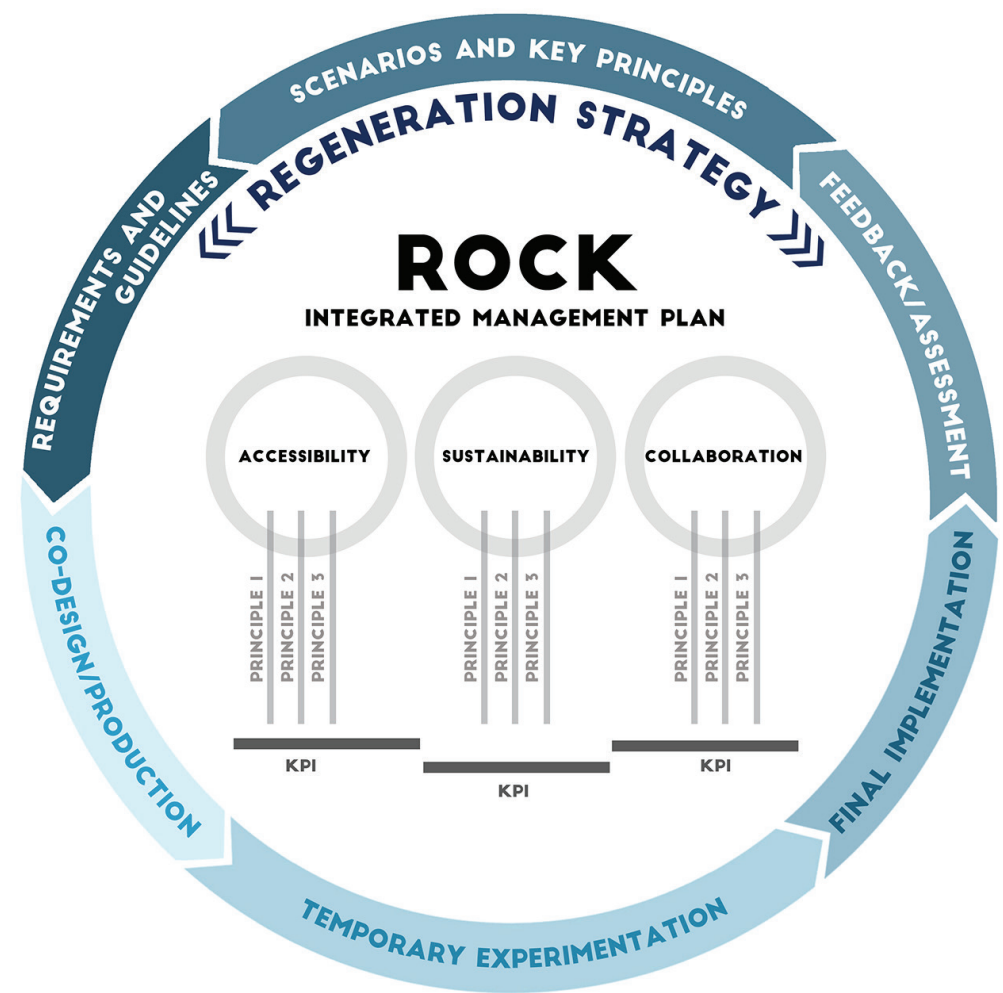

Figure 2: The ROCK Integrated Management Plan: design and implementation process.

Source: Graphic design by Chiara Mariotti. 
The evaluation process regarding the significance of scenarios and their principles, as well as the selection and implementation of regeneration pilot actions, is carried out with a 'living lab' approach and will be checked, monitored and updated thanks to the support of suitable Key Performance Indicators.

Therefore, the ROCK strategic regeneration process starts after the scenario construction and the guiding principles identification, and consists of the following circular steps:

- requirements definition and guidelines assumption to orient activities with clear objectives and rules;

- co-design and co-production activities for supporting a multi-actors process;

- temporary and final experimentation to give effect to urban transformations;

- feedback system so as to assess in a quantitative and qualitative way the response to implemented actions.

Through the description of the ROCK IMP design process, this paper wants to transmit the complexity of long-lasting social, economic, environmental and cultural dynamics activated by the project. The following section gives a more concrete perspective describing what is especially being done in Bologna.

\subsection{First applications in Bologna ROCK city}

The experience of Bologna is one of the most interesting because two Management Plans are currently under construction: the ROCK Integrated Management Plan, as the main output of H2020 research activities, and the UNESCO Management Plan, as the key document supporting city porticoes' candidacy into the UNESCO World Heritage Lists.

The Bologna demo site is the University area (called $U$-Zone by ROCK) located inside the historic city centre and developed over time along Via Zamboni, one of the major street characterized by the presence of typical Bolognese porticos and urban squares (Piazza Ardigò, Piazza Rossini, Piazza Verdi, Piazza Scaravilli e Piazza Puntoni), and rich in cultural and artistic institutions and museums. Nevertheless, this cultural heritage is not fully known and exploited by citizens and tourists and frequent social conflicts have arisen from the forced coexistence between residents and student population.

The selected pilot actions are the result of a process of community involvement (named $U-L a b)$ to create a local Ecosystem of Stakeholders and to enable the co-designed and co-construction process (U-Atelier). According to the IMP structure, a first diagnostic phase aimed to underline constraints at different levels has been addressed, followed by the identification of needs and priorities that can boost actions implementation.

During the two years of ROCK project, different types of actions have been carried out in the U-Zone, each one inserted in a global vision, concurring to achieve integrated targets and objectives and according with the vocation of single spaces (indoor and outdoor, public and private).

New lightscape is one of the already implemented actions involving Via Zamboni and its surrounding areas. For several years, phenomena of social degradation and physical decay have been reducing the sense of security and restricting use and fruition of the area, especially in the night. During thematic participative tables and on-site meetings, involving also disability manager and associations of people with disabilities, the need to rethink lighting along the historical axis of Via Zamboni strongly emerged as possible strategy to improve accessibility (Fig. 3). Thus, new lightscape has been conceived by Viabizzuno - partner of the 


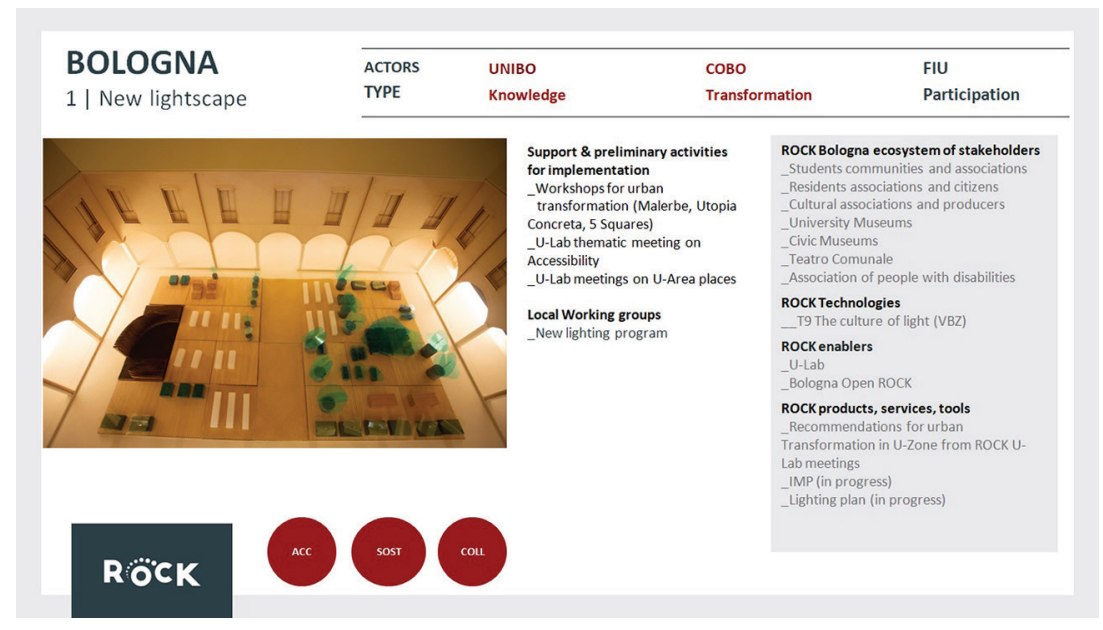

Figure 3: New lightscape overview table.

Source: U-lab and U-Atelier.

ROCK project - as an experimentation of innovative lighting concept that tests effective solutions to combine physical accessibility and security of public spaces with cultural heritage enhancement. The lighting project intends to valorise the historic setting through the adoption of specific solutions designed for the peculiar configuration of spaces, environmental conditions and features of buildings. Light contributes to a better perception of volumes, distinction between voids and solids, colours, movements. Besides, the light is conceived as a detector of hidden treasures and points out their presence, treating the city as an art gallery, for example showcasing significant architectural details (Fig. 4).

The project takes into account the variability of the use of spaces and kinds of users in relation with the different times of fruition, modulating the lighting system into: light to meet (from dusk until 19:30), light for break (from 19.30 to 20.30), light for architecture and art (from 20:30 to 23:30), and light for sleeping (from 23:30 until sunrise). Therefore, the developed guiding criteria closely link the use of light to the fruition of public space, intervening on the environment as a system of structural interrelationships between an individual and its relevant space.

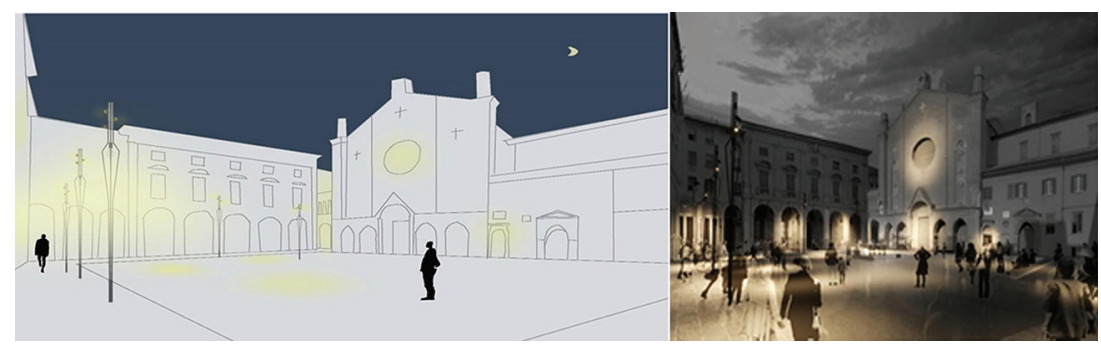

Figure 4: Lighting project for Piazza Rossini and its simulation.

Source: Viabizzuno. 

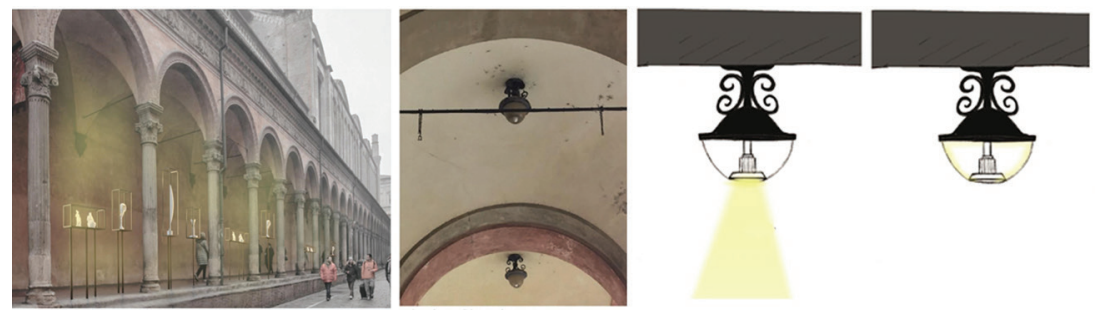

Figure 5: Via Zamboni porticos: display-cases for temporary exhibitions and historical lanterns subjected to conservative restoration.

Source: Viabizzuno.

The project includes the restoration of the historical lanterns under the porticoes and the conservation of the old notice boards, still affixed to the walls, with the addition of integrated lighting to show their contents clearly. New display-cases for art works and temporary exhibitions have been also designed, resistant to vandalism thanks to a base fixed to the floor and characterized by a downward light tracing the path and lighting the surrounding area; bicycle carriers with integrated light improve safety as well as information totems helps people get historical information and orient themselves (Fig. 5). The project integrates technical competences based on the research of Viabizzuno. All the designed solutions concur to literally put the area under a new light: improve physical accessibility, increase safety, enhance cultural heritage, encourage public events, support new forms of sociality and inclusion, and promote a new urban storytelling.

The positive outcome of these urban transformations confirms the role of lighting as key action to focus on in order to cluster a set of vital experimentations, which can guide the action planning to be included in Bologna ROCK Integrated Management Plan.

\section{CONCLUSION AND OPEN ISSUES}

This paper has described the ROCK experimentation on cultural heritage-led regeneration strategies for historic sustainable cities. The heart of the investigation has focused on the design and implementation phases of a new governance tool, the Integrated Management Plan, capable of supporting a multi-level integration - plans, procedures, policies, actors and processes - and harmonizing cultural heritage conservation and enhancement, and sustainable development in a long-term perspective.

As ROCK is an experimental research and the construction of the Integrated Management Plan is still ongoing, it is necessary to point out that, on one hand, many of the addressed questions are still evolving and that, on the other hand, there is no lack of open issues. Nevertheless, the ROCK project has several strong points, such as the ability to broaden participation in planning long-term management for historic cities. From this point of view, the importance of the 'democratic participation' and the creation of 'heritage communities', both recommended by the Framework Convention on the Value of Cultural Heritage for Society (Faro Convention), is strongly confirmed [19]. Another crucial factor is the concept of 'integration' - expressed also in the name of this tool - intended as the need to promote a governance instrument capable of activating new social, economic and cultural dynamics, strongly rooted in each urban local context. In this regard, Bologna is a far-sighted example: the city candidacy for porticoes into the UNESCO World Heritage Lists is in fact benefitting from the Integrated Management Plan put in place by ROCK and vice-versa, in an innovative 
perspective that recognizes the transversal value of cultural heritage management for future generations. The Municipality of Bologna is working together with the Research Group of the University of Bologna to draft this plan, whose guidelines will be disseminated at the end of the design process. The on-site actions allow to test strategies and to point out constraints, barriers and unexpected positive implications, as happened thanks to the described New lightscape, which highlighted the opportunities to preserve cultural heritage and enhance its accessibility by working on immaterial aspects.

In conclusion, the main innovative contribution coming from ROCK project is the Roadmap for sustainable Cultural Heritage Management in historic cities. To achieve this goal, some open issues, specifically related to ROCK Integrated Management Plan, have to be deepened and solved, such as the authorship, duration and territorial area of the plan as well as the strategy to keep it alive after the end of the project; these are all essential queries that will be addressed in the ongoing phases of the project.

\section{ACKNOWLEDGEMENTS}

ROCK project is funded by European Union's Horizon 2020 Research and Innovation Programme (call H2020-SC5-2016-2017, Grant Agreement n. 730280).

\section{REFERENCES}

[1] European Commission, Using culture to breathe new life into historic city centres, 18 June 2019. Online, https://cordis.europa.eu/news/rcn/131357/en (accessed 01 July 2019.)

[2] European Commission, Horizon 2020, Work Programme 2016-2017 - 12. Climate action, environment, resource efficiency and raw materials, 24 April 2017. Online, https:/ec.europa.eu/research/participants/data/ref/h2020/wp/2016_2017/main/ h2020-wp1617-climate_en.pdf (accessed 01 July 2019).

[3] ROCK Official Website. Online, https://rockproject.eu (accessed 01 July 2019).

[4] Veldpaus, L., Historic Urban Landscapes: Framing the Integration of Urban and Heritage Planning in Multilevel Governance, Technische Universiteit Eindhoven: Eindhoven, 2015.

[5] European Commission, Horizon 2020 Cultural Heritage and European Identities. List of projects 2014-2017. Directorate-General for Research and Innovation Open and inclusive Societies, 2018. Online, https://ec.europa.eu/research/social-sciences/pdf/ project_synopses/cultural_heritage_projects.pdf (accessed 01 July 2019).

[6] UNESCO, Recommendation on the Historic Urban Landscape, Paris, 10 November 2011. Online, https://whc.unesco.org/uploads/activities/documents/activity-638-98.pdf (accessed 01 July 2019).

[7] UNESCO, Convention concerning the Protection of the World Cultural and Natural Heritage, 1972. Online, https://whc.unesco.org/en/conventiontext/ (accessed 04 July 2019).

[8] Jokilehto, J., Definition of Cultural Heritage. References to Documents in History. ICCROM Working Group "Heritage and Society", 2005. Online, http://cif.icomos.org/ pdf_docs/Documents\%20on\%20line/Heritage\%20definitions.pdf (accessed 04 July 2019).

[9] Sonkoly, G. \& Vahtikari, T., Innovation in Cultural Heritage Research. For an integrated European Research Policy, Directorate-General for Research and Innovation Europe in a changing world - Inclusive, innovative and reflective societies (Horizon 2020/SC6) 
and Cooperation Work Programme: Socio-Economic Sciences and Humanities (FP7), Publications Office of the European Union in Luxembourg, 2018. doi: 10.2777/673069. Online, https://publications.europa.eu/en/publication-detail/-/publication/1dd62bd12216-11e8-ac73-01aa75ed71a1(accessed 04 July 2019).

[10] UNESCO, ICCROM, ICOMOS, IUNC, Managing Cultural World Heritage, UNESCO World Heritage Centre - World Heritage Resource Manual: Paris, 2013. Online, https:// whc.unesco.org/document/125839 (accessed 04 July 2019).

[11] UNESCO, Operational Guidelines for the Implementation of the World Heritage Convention, UNESCO World heritage Centre: Paris, 2017. Online, https://whc.unesco. org/en/guidelines/ (accessed 04 July 2019).

[12] UNESCO, Management planning of the UNESCO World Heritage Sites. Guidelines for the development, implementation and monitoring of management plans. With the examples of Adriatic WHS, Expeditio: Kotor, 2016. Online, https://www.expoaus.org/ upload/novosti/publication_expoaus_eng_web_105355.pdf (accessed 04 July 2019).

[13] European Commission, Getting cultural heritage to work for Europe. Report on the Horizon 2020 Expert Group on Cultural Heritage, Directorate-General fro Research and Innovation, Publications Office of the European Union: Luxembourg, 2015. Online, https://www.kowi.de/Portaldata/2/Resources/horizon2020/coop/H2020-ReportExpert-Group-Cultural-Heritage.pdf (accessed 05 July 2019).

[14] Council of the European Union, Conclusions on cultural heritage as a strategic resource for a sustainable Europe, Brussels, 20 May 2014. Online, https://www.consilium.europa. eu/uedocs/cms_data/docs/pressdata/en/educ/142705.pdf (accessed 05 July 2019).

[15] LOCUS Consulting Ltd, Liverpool Maritime Mercantile City World Heritage Site Management Plan 2017-2024, 2017. Online, http://regeneratingliverpool.com/wpcontent/uploads/2017/07/PMD-486-Liverpool-WHS-Management-Plan-FINAL-VERSION-as-at-12-May-2017.pdf (accessed 06 July 2019).

[16] Mission site historique de Lyon - Direction des affaires culturelles, Plan de Gestion du site historique de Lyon. Inscrit sur la liste du patrimoine mondial de l'UNESCO, 2013. Online, http://whc.unesco.org/fr/documents/138552/ (accessed 06 July 2019).

[17] HERO - HERitage as Opportunity, Local Action Plan. Vilnius Old Town, 2011. Online: https://urbact.eu/sites/default/files/vilnius_action_plan.pdf (accessed 06 July 2019).

[18] Gaspari, J., Boulanger, S.O.M. \& Antonini, E., Multi-Layered design strategies to adopt smart districts as urban regeneration enablers. In International Journal of Sustainable Development and Planning, 12(8), pp. 1247-1259, 2017. Online, https://www.witpress. com/Secure/ejournals/papers/SDP120801f.pdf (accessed 06 July 2019).

[19] Council of Europe, Framework Convention on the Value of Cultural Heritage for Society, Faro, 27 October 2005. Online, https://rm.coe.int/1680083746 (accessed 07 July 2019). 